Gut, 1967, 8, 612

\title{
Reversal of non-Addisonian achlorhydria by a Roux-en-Y loop
}

\author{
W. M. CAPPER, T. J. BUTLER, AND J. O. KILBY \\ From the Departments of Gastroenterology, Southmead and Frenchay Hospitals, Bristol
}

EDITORIAL COMMENT A patient with symptomatic achlorhydria has shown some improvement and some increase in acid secretion following excision of the pylorus and distal antrum followed by gastro-jejunal anastomosis using a Roux-en-Y loop.

In a previous paper in this Journal (Capper, Butler, and Buckler, 1966b) it was shown that duodenal reflux over gastric mucosa in man causes atrophic gastritis and production of acid is depressed. Whether the oxyntic cells would regain normal function if regurgitation were abolished has remained in doubt. It has been possible to put this problem to the test under the following circumstances.

\section{CASE REPORT}

An ex-schoolteacher housewife aged 57 was first seen in October 1965 and gave a history of increasing flatulent dyspepsia for four years. It started soon after breakfast and continued more or less all day but disappeared when she lay down and relaxed. The pain was made worse by fat and the symptoms had a definite periodicity of eight to 10 weeks' activity and then she became symptom free for three to five weeks. She also complained of burning in the epigastrium passing up behind the sternum with occasional dysphagia and regurgitation of yellowish fluid. She had slowly become depressed and miserable under these symptoms and spent much of the day lying in bed, which position gave her relief. A milk diet, if anything, made the symptoms worse and she benefited from stimulants such as sauces and spicy food. Repeated barium meals, cholecystograms and, on one occasion, oesophagoscopy, revealed no abnormality. Haemoglobin was $92 \%$ and her symptoms were regarded as psychogenic in origin. An augmented histamine test in November 1965 showed a basal acid level of $0.6 \mathrm{mEq}$. per hour and a maximal acid output of $1 \mathrm{mEq}$. per hour. A pyloric regurgitation test (Capper, Airth, and Kilby, 1966c) in November 1965 showed persistent reflux when the patient was standing but this ceased when she lay down. A diagnosis of hypochlorhydria, probably due to an atrophic gastritis, was made with a note to repeat the augmented histamine test every six months. In May 1966 the symptoms were getting steadily worse and the augmented histamine test was repeated; no basal acid was present and there was a maximal titratable acidity after histamine of $0.46 \mathrm{mEq}$. per hour. The haemoglobin remained at $92 \%$ and the red cells were classified as normal. It was, therefore, resolved to stop the regurgitation and, accordingly, in July 1966 a Roux-en-Y operation was carried out excising the distal two inches of the pyloric antrum and making the anastomosis about 10 inches from the duodeno-jejunal junction.

The section taken from the upper anterior body of the stomach was reviewed by Dr. Norman Brown and the late Professor H. A. Magnus and showed normal gastric mucosa.

Three months later the patient had lost all her symptoms apart from occasional minimal dysphagia. Improvement and well-being were such that she returned to normal housework and gardening, neither of which had been possible during the previous four years. In November 1966 the augmented histamine test result showed an acid output of $14.4 \mathrm{mEq}$. in the post-histamine hour thou $h$ there was still no basal acid.

\section{DISCUSSION}

Our interpretation of these findings is that some factor which impairs normal acid secretion was removed by the Roux-en-Y operation. There are two possible reasons for the disturbance of acid production following regurgitation of duodenal juice: (1) development of atrophic gastritis (Capper et al., 1966; Lawson, 1964); (2) Davenport has shown that hydrogen ions produced by histologically normal oxyntic cells may diffuse back into the cell following mucosal irritation with various chemical substances (Davenport, 1964; Davenport, Warner, and Code, 1964; Davenport, 1965). A similar effect is produced by bile (Davenport, Personal communication, 1967).

The fall in acid produced by duodenal regurgitation is likely to be a sum of these two factors in varying proportions. Certainly dysfunction of the 
residual parietal cells due to a disturbance of the electro-chemical barrier at the surface of the cell is of great importance. Why these two factors should be present in varying proportions under different circumstances is not known but they must both be considered in a case such as this. The duration of exposure to bile is probably of significance in this respect. Further evidence of the return of acid secretion when mucosal integrity is restored is seen in the healing of a gastric ulcer (Capper, Butler, Buckler, and Hallett, 1966a).

\section{SUMMARY AND CONCLUSION}

A case is described in which the gastric hyposecretion associated with duodenal regurgitation progressed almost to an achlorhydria. Abolition of the regurgitation by a Roux-en-Y procedure produced a return of acid to normal levels and resolution of the dyspeptic symptoms. It appears probable that duodenal juices in contact with gastric mucosa were responsible for the impairment in acid output. The possible mechanisms involved are discussed.

\section{REFERENCES}

Capper, W. M., Butler, T. J., Buckler, K. G., and Hallett, C. P. (1966a). Variation in size of the gastric antrum: measurement of alkaline area associated with ulceration and pyloric stenosis. Ann. Surg., 163, 281-290.

- (1966b). Alkaline areas in gastric mucosa after gastric surgery. Gut, 7, 220-222.

- , Airth, G. R., and Kilby, J. O. (1966c). A test for pyloric regurgitation. Lancet, 2, 621-623.

Davenport, H. W. (1964). Gastric mucosal injury by fatty and acetylsalisylic acids. Gastroenterology, 46, 245-253.

-, Warner, H. A., and Code, C. F. (1964). Functional significance of gastric mucosal barrier to sodium. Ibid., 4, 142-152.

- (1965). Is the apparent hyposecretion of acid by patients with gastric ulcer a consequence of a broken barrier to diffusion of hydrogen ions into the gastric mucosa? Gut, 6, 513.

- (1967). Personal communication.

Lawson, H. H. (1964). Effect of duodenal contents on the gastric mucosa under experimental conditions. Lancet, 1, 469-472. 